Strategi AMBT untuk Meningkatkan Kemampuan Membaca Pemahaman Interpretatif Siswa Kelas IV SD

Article · December 2019

CITATIONS

0

3 authors, including:

Susiati Susiati

Universitas iqra buru

27 PUBLICATIONS 110 CITATIONS

SEE PROFILE

Some of the authors of this publication are also working on these related projects:

METODE PEMBELAJARAN SOSIODRAMA View project

Linguist View project 


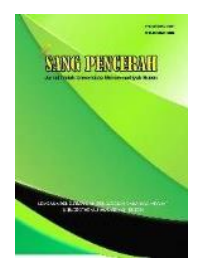

SANG PENCERAH

Volume 5 Issue 2, 2019

P-ISSN : 2528-360X, E-ISSN : 2621-6159

Website: https://www.jurnal-umbuton.ac.id/index.php/Pencerah

\title{
Strategi AMBT untuk Meningkatkan Kemampuan Membaca Pemahaman Interpretatif Siswa Kelas IV SD Negeri 3 Namlea Kabupaten Buru
}

\author{
1Taufik, ${ }^{1}$ Susiati, ${ }^{1}$ Nur Fadhilah Amir
}

\begin{abstract}
The ability to read is essential for students because it can increase knowledge. This study aims to describe the improvement in reading comprehension of grade IV students at SD Negeri 3 Namlea Buru Regency through the AMBT Strategy. The results of the repetition analysis in the last two years, especially the ability to read interpretive understanding, are included in the lowest value. This research was conducted in the first semester of the 2018/2019 academic year. Data sources in this study are students and teachers. The type of data in this study is quantitative data obtained from test results and qualitative data collected through observation sheets. The results showed that students' interpretive reading ability or mastery learning in the first cycle was $65 \%$, with an average value of 72.5 increasing in the second cycle by $90 \%$ with an average cost of 82.9. The percentage of teacher activity in the first cycle was $63.15 \%$, and the second meeting was $73.68 \%$, increasing in the second cycle. The first meeting was $84.21 \%$, and the second meeting was $89.47 \%$. The percentage of student activity in the first cycle was $60 \%$, and the second meeting, $70 \%$, increased in the second cycle, $80 \%$, and the second meeting was $90 \%$. From these results, it can be concluded that the implementation of the AMBT strategy can improve the interpretive reading skills of fourth-grade students at SD Negeri 3 Namlea, Buru Regency.

Keywords: Interpretative; AMBT Strategy; Cycle
\end{abstract}

\begin{abstract}
Abstrak
Kemampuan membaca merupakan hal yang penting bagi siswa karena dapat meningkatkan pengetahuan. Penelitian ini bertujuan untuk mendeskripsikan peningkatkan kemampuan membaca pemahaman interpretatif siswa kelas IV SD Negeri 3 Namlea Kabupaten Buru melalui Strategi AMBT). Hasil analisis ulangan pada dua tahun terakhir khususnya kemampuan membaca pemahaman interpretatif termasuk dalam nilai yang paling rendah. Penelitian ini dilaksanakan pada semester I tahun pelajaran 2018/2019. Sumber data dalam penelitian ini adalah siswa dan guru. Jenis data dalam penelitian ini adalah data kuantitatif yang diperoleh dari hasil tes dan data kualitatif yang diperoleh melalui lembar observasi. Hasil penelitian menunjukkan bahwa kemampuan membaca interpretatif siswa atau ketuntasan belajar pada siklus I sebesar $65 \%$ dengan nilai rata-rata 72,5 meningkat pada siklus II sebesar $90 \%$ dengan nilai rata-rata 82,9 . Persentase aktivitas guru siklus I pertemuan pertama sebesar $63,15 \%$ dan pertemuan kedua sebesar $73,68 \%$ meningkat pada siklus II pertemuan pertama sebesar $84,21 \%$ dan pertemuan kedua sebesar $89,47 \%$. Persentase aktivitas siswa siklus I pertemuan pertama sebesar $60 \%$ dan pertemuan kedua sebesar $70 \%$ meningkat pada siklus II pertemuan pertama sebesar $80 \%$ dan pertemuan kedua sebesar $90 \%$. Dari hasil tersebut dapat disimpulkan bahwa penerapan strategi AMBT dapat meningkatkan kemampuan membaca interpretatif siswa kelas IV SD Negeri 3 Namlea Kabupaten Buru.

Kata Kunci: Interpretatif; Strategi AMBT; Siklus
\end{abstract}

$\overline{{ }^{1} \text { Universitas Iqra Buru, Indonesia, email: taufiksalamun@gmail.com }}$ 


\section{PENDAHULUAN}

Pembelajaran membaca di sekolah dasar, siswa harus banyak di hadapkan dengan berbagai ragam bacaan. Selanjutnya, mereka dapat berkomunikasi dengan gagasan yang dituangkan dalam bahasa tulis tersebut. Berbagai keterampilan membaca harus dilatihkan kepada mereka agar kepemilikan keterampilan itu bermanfaat dalam kehidupan sehari-hari (Nurhadi, 2004).

Tarigan (1990) mengatakan bahwa membaca adalah suatu proses yang dilakukan serta dipergunakan oleh pembaca untuk memperoleh pesan yang hendak disampaikan penulis melalui kata-kata dalam bahasa tulis. Lebih lanjut Khasanah (2016: 162) menambahkan bahwa membaca merupakan keterampilan berharga dapat digunakan sepanjang hidup. Membaca yang baik ditunjukkan dengan kemampuan seseorang menyelesaikan tugas membaca dengan mudah dan cepat disertai peningkatan pemahaman sehingga memperoleh nilai lebih baik dan belajar dengan cepat.

Suatu proses yang menuntut pembaca agar dapat memahami kelompok kata yang tertulis merupakan suatu kesatuan dan terlihat dalam suatu pandangan sekilas, dan makna kata-kata itu dapat diketahui secara tepat. Apabila hal ini dapat terpenuhi maka pesan yang tersurat dan tersirat dapat dipahami sehingga proses membaca sudah terlaksana dengan baik. Sejalan dengan itu, Nurhadi (2004) mengungkapkan bahwa membaca merupakan salah satu kegiatan aktif mencari informasi yang kita dapat dalam bacaan. Dengan sendirinya, kebiasaan-kebiasaan membaca akan mebuka cakrawalaberfikir dalam menghadapi suatu masalah. Dalam membaca, diharapkan pembaca memahami apa yang dibaca, sehingga tujuan yang di tetapkan dapat tercapai dengan baik.

Seseorang yang sedang membaca berarti ia sedang melakukan suatu kegiatan dalam bentuk berkomunikasi dengan diri sendiri melalui lambang tertetulis. Makna bacaan tidak terletak pada bahan tertulis saja, tetapi juga terletak pada pikiran membaca itu sendiri. Dengan demikian makna bacaan bisa berubah-ubah bergantung pada pembaca dan pengalaman berbeda yang dimilikinya pada waktu pembaca dan dipergunakannya untuk menafsirkannya kata-kata tulis tersebut. Seorang pembaca yang baik adalah seorang yang dapat mengambil tanggapan mengenai bahasa (ide dan kematangan pengarang) dan pengertian dengan kecepatan yang lumayan (Mintowati, 2003).

Supriadi (1999) menjelaskan kemampuan membaca yang baik merupakan hal yang sangat penting dalam suatu bacaan. Dalam hal ini guru mempunyai peranan yangsangat besar untuk mengembangkan serta meningkatkan kemampuan yang dibutuhkan dalam membaca. Usaha yang dapat dilakukan guru diantaranya: (1) dapat menolong para siswa untuk memperkaya kosakata mereka dengan jalan memperkenalkan sinonim kata-kata, antonim, imbuhan, dan menjelaskan arti suatu kata abstrak dengan mempergunakan bahasa daerah atau bahasa ibu mereka, (2) dapat membantu para siswa untuk memahami makna struktur-struktur kata, kalimat dan disertai 
latihanseperlunya, dan (3) dapat meningkatkan kecepatan membaca para siswa dengan menyuruh mereka membaca dalam hati, menghindari gerakan bibir, danmenjelaskan tujuan membaca.

Kemampuan membaca merupakan sesuatu yang vital dalam suatu masyarakat terpelajar. Melalui membaca siswa akan memperoleh pengalaman dan pengetahuan yang lebih luas untuk dapat mengembangkan ide dan gagasan. Keberhasilan belajar mereka dalam mengikuti proses kegiatan belajar mengajar di sekolah sangat ditentukan oleh penguasaan kemampuan membaca mereka karena dengan membaca siswa mendapatkan banyak informasi dan pengetahuan.

Membaca di Sekolah Dasar (SD) pada hakikatnya terbagi atas dua bagian, yaitu membaca permulaan pada kelas 1-2 dan membaca lanjut atau membaca pemahaman untuk kelas 3-6. Dalam kurikulum telah ditetapkan bahwa untuk siswa kelas 36 adalah membaca lanjut atau disebut juga membaca pemahaman, karena tujuannya adalah agar anak mampu memahami makna dan mengambil manfaat dalam pesan yang disampaikan penulis kepada pembaca (siswa). Menurut Krismanto (2015: 234) masyarakat akan cenderung lebih cepat mengalami, mengantisipasi dan menyesuaikan dengan berbagai perubahan dan kemajuan ketika individu-individu yang ada dilam masyarakat itu memiliki kemampuan dan budaya membaca yang tinggi. Sebaliknya ketika sebuah masyarakat memiliki kemampuan dan budaya yang rendah akan relatif lebih lambat dalam menyesuaikan dengan perubahan-perubahan yang terjadi di sekitarnya.

Menurut Burn, Roe dan Roess, (dalam Ritawati dkk, 2005) ada dua tipe pemahaman, pertama pemahaman literal (literal compherension), yaitu jenis pemahaman lebih dasar, kedua pemahaman yang lebih tinggi yang meliputi (1) pemahaman interpretatif

(2) pemahaman kritis (3) dan pemahaman kreatif. Penelitian ini membatasi hanya pada tingkat pemahaman yang pertama, yaitu pemahaman interpretatif. Pemahaman interpretatif yaitu pemahaman yang dihasilkan oleh suatu proses perolehan ide-ide yang tidak dinyatakan secara langsung dalam bacaan.

Menurut Ritawati (2005) pemahaman interpretatif ini, merupakan pemahaman yang lebih tinggi dari pemahaman literal. Jenis pemahaman ini dihasilkan melalui proses berpikir yang lebih tinggi seperti menginterpretasi, analisis, dan sintesis informasi. Dalam pemahaman ini, prediksi suatu bacaan merupakan keterampilan yang penting. Dengan memprediksikan sesuatu, seseorang dapat membuat hipotesis yang diikuti dengan penerimaan atau penolakan terhadap hipotesis itu. Pemahaman ini lebih menuntut kemampuan menafsirkan fakta dan informasi dalam bacaan. Pemahaman interpretatif mencakup kemampuan antara lain (1) membuat kesimpulan, (2) membuat generalisasi, (3) mencari hubungan sebab akibat, (4) membuat perbandingan, dan (5) menemukan hubungan antar proposisi.

Dalam membaca pemahaman interpretatif, siswa dituntut untuk memahami isi bacaan yang dibacanya secara tersirat. Hal ini sejalan dengan 
Burns (dalam Syafi'ie, 1999) dinyatakan secara lansung. menyebutkan bahwa untuk Pemahaman interpretatif ini, memperoleh pemahaman interpretatif, merupakan pemahaman yang lebih pembaca harus mampu menangkap tinggi dari pada pemahaman literal. apa yang tersirat dalam wacana Jenis pemahaman ini dihasilkan sehingga siswa mudah membuat melalui proses berpikir yang lebih kesimpulan bacaan dan ide pokok tinggi seperti menginterpretasi, pada isi bacaan pada tiap paragraf analisis dan sintesis informasi. Dalam terhadap wacana yang dibacanya. Untuk mendapatkan ide pokok dalam membaca siswa harus berpikir bersama penulis dari bacaan tersebut. Lazimnya ide pokok berada di awal paragraf, di tengah paragraf, di akhir paragraf, di awal dan akhir paragraf, serta berada diseluruh paragraf.

Kemampuan tiap siswa berbeda dalam memahami apa yang dibaca untukmendapatkan ide pokok. Hal ini bergantung pada perbendaharaan kata yang dimiliki, minat, jangkauan mata, kecepatan interpretasi, latar belakang pengalaman sebelumnya, kemampuan intelektual, keakraban dengan ide yang dibaca. Hal itu juga berlaku pada siswa yang telah duduk di bangku kelas IV Sekolah Dasar.

Siswa kelas IV SD diharapkan sudah mampu membaca pemahaman interpretatif khususnya dalam menentukan ide pokok dan menarik kesimpulan dalam suatu bacaan, karena menentukan ide pokok dan menarik kesimpulan akan membantu siswa dalam memahami isi suatu bacaan. Selain itu, diharapkan guru mengajarkan materi menentukan ide pokok dengan jalan membimbing siswa secara terpadu sesuai dengan prosedur atau tahapan yang menjadi bagian dari membaca pemahaman interpretif tersebut.

Membaca

pemahaman interpretatif merupakan proses memperoleh ide-ide yang tidak pemahaman ini, prediksi suatu bacaan merupakan keterampilan yang penting. Dengan memprediksi seseorang dapat membuat hipotesis, yang diikuti dengan penerimaan atau penolakan dengan hipotesis itu. Pemahaman ini lebih menuntut kemampuan menafsirkan fakta dan informasi dalam bacaan. Pemahaman interpretatif mencakup kemampuan antara lain (1) membuat kesimpulan, (2) membuat generalisasi, (3) mencari hubungan sebab akibat, (4) membuat perbandingan, (5) menemukan hubungan antar proposisi, Ritawati (2005).

Gillet dan temple, (Syafi'ie, 1999) mengatakan bahwa proses pemahaman dalam membaca melibatkan tiga hal pokok, yaitu pengetahuan yang telah dimiliki oleh pembaca, pemahaman tentang struktur teks, dan kegiatan menemukan makna. Sehubungan dengan teori membara ini, guru yang efektif seharusnya mampu mengarahkan siswa agar lebih banyak mengunakan pengetahuan topik untuk memproses ide dan pesan suatu teks. Skemata adalah latar belakang pengetahuan dan pengalaman yang telah dimiliki siswa tentang suatu informasi atau konsep tentang sesuatu.

Tujuan membaca pemahaman interpretatif adalah agar siswa mampu mengambil manfaat dan pesan yang disampaikan penulis kepada pembaca 
(siswa). Dengan kata lain, siswa diharapkan mampu memahami isi bacaan, mampu membuat kesimpulan isi bacaan, membuat generalisasi, mampu mencari hubungan sebab akibat, mampu membuat perbandigan, mampu menemukan hubungan antar proposisi Ritawati (2005).

Selain siswa itu sendiri, guru atau pendidik pun ikut berperan penting dalam hal peningkatan kemampuan membaca pemahaman. Penerapan strategi pembelajaran yang sesuai dengan materi pelajaran, dapat mendorong terciptanya proses belajar mengajar yang kondusif. Salah satu strategi yang dapat digunakan dalam upaya peningkatan kemampuan membaca pemahaman tersebut adalah strategi Aktivitas Membaca Berpikir Terbimbing (AMBT).

Strategi aktivitas membaca berpikir terbimbing adalah sebagai salah satu bentuk pembelajaran membaca dan keterampilan berbahasa di SD. Strategi ini berguna dalam membimbing siswa untuk berinteraksi dengan teks berlandaskan pada pendekatan proses membaca dimulai dari tahap prabaca, saatbaca, pascabaca.

Berdasarkan hasil analisis hasil ulangan harian siswa kelas IV SD Negeri 3 Namlea pada 2 tahun terakhir yakni tahun pelajaran 2016/2017 dan tahun pelajaran 2017/2018 khususnya kemampuan membaca pemahaman interpretatif termasuk nilai yang paling rendah dari empat keterampilan berbahasa. Hal ini terlihat dari presentase ketuntasan klasikal maun nilai rata-rata yang diperoleh siswa. Pada tahun pelajaran 2016/2017, dari 28 siswa kelas IV hanya 17 orang yang tuntas atau $60,71 \%$ dengan nilai rata-rata 65,5 sedangkan pada tahun pelajaran 2017/2018 dari 28 siswa, hanya 19 orang yang tuntas atau $67,85 \%$ sedangkan strandar ketuntasan minimal yang ditetapkan sekolah $70 \%$ (ketuntasan individu). Hal ini menunjukkan bahwa dalam melaksanakan pembelajaran khususnya membaca pemahaman interpretatif, guru perlu melakukan proses kreatif untuk meningkatkan hasil belajar siswa. Oleh sebab itu, penelitian ini bertujuan untuk mendeskripsikan peningkatkan kemampuan membaca pemahaman interpretatif siswa kelas IV SD Negeri 3 Namlea Kabupaten Buru melalui Strategi Aktivitas Membaca Berpikir Terbimbing (AMBT). Selain itu, tujuan penelitian ini juga untuk mengetahui aktivitas guru dan siswa dalam proses pembelajaran dengan menerapkan Strategi Aktivitas Membaca Berpikir Terbimbing (AMBT).

\section{METODE PENELITIAN}

\subsection{Metode Penelitian}

Arikunto (2010) mengatakan bahwa metode penelitian adalah cara yang dilakukan oleh peneliti dalam pengumpulan data penelitiannya. Oleh sebab itu, keberhasilan dalam melakukan sebuah penelitian ilmiah sangat ditentukan oleh metode yang digunakan. Metode yang di gunakan dalam penelitian ini adalah metode deskriptif kuantitatif dan kualitatif. Metode deskriptif kuantitatif berupa angka-angka dan analisis berdasarkan statistik, Sugiyono (2010). Metode ini digunakan untuk menentukan nilai hasil belajar siswa. Sedangkan metode deskriptif kualitatif, berhubungan lansung dengan pengumpulan data 
dan pengkajian data dalam laporan penelitian. Penggunaan metode ini bertujuan untuk mendeskripsikan secara sistematis, faktual dan akurat mengenai data, sifat-sifat serta hubungan fenomena-fenomena yang diteliti khususnya data tentang proses pelaksanaan pembelajaran.

\subsection{Jenis Penelitian}

Penelitian ini termasuk jenis penelitian tindakan kelas (classroom action research), karena penelitian dilakukan untuk memecahkan masalah pembelajaran di kelas. Penelitian tindakan kelas adalah suatu bentuk kajian yang bersifat reflektif oleh pelaku tindakan yang dilakukan untuk meningkatkan kemantapan rasional dari tindakan mereka danmelaksanakan tugas, memperdalam pemahaman terhadap tindakan-tindakan yang dilakukan itu, serta memperbaiki kondisi dimana praaktek pembelajaran tersebut dilakukan.

\subsection{Populasi Penelitian}

Populasi adalah keseluruhan subjek penelitian, Arikunto (2007), mengatakan bahwa apabila ingin meneliti semua elemen yang ada diwilayah penelitian, maka penelitiannya merupakan penelitian populasi.

Populasi penelitian ini adalah seluruh siswa kelas IV SD Negeri 3 Namlea Kabupaten Buru yang terdiri dari satu kelas dengan jumlah siswa 20 orang yang terdiri atas 6 orang siswa laki-laki dan 14 orang siswa perempuan.

\subsection{Sampel Penelitian}

Sampel yang digunakan dalam penelitian ini sesuai dengan pendapat
Arikunto (2007) bahwa apabila subjeknya (anggota populasi) kurang dari 100 lebih baik di ambil semuanya, sehingga penelitian ini merupakan penelitian populasi. Selanjutnya jika subjeknya lebih besar dapat diambil antara $10-15 \%$ atau $20-25 \%$ atau lebih, tergantung pada keterampilan peneliti dilihat dari waktu, tenaga, dan dana. Populasi penelitian ini hanya berjumlah 20 orang siswa, maka populasi sebanyak 20 orang siswa tersebut langsung ditetapkan sebagai sampel penelitian atau menggunakan sampel total.

\subsection{Teknik Pengumpulan Data}

Sumber data dalam penelitian ini adalah siswa dan guru. Jenis data adalah data kuantitatif dan data kualitatif. Data kuantitatif digunakan untuk menentukan nilai hasil belajar siswa pada setiap siklus tindakan pembelajaran yang dilakukan oleh guru dalam menerapkan strategi AMBT dengan menggunakan test evaluasi, sedangkan data kualitatif digunakan untuk menghimpum data tentang proses pelaksanaan pembelajaran dengan menggunakan lembar observasi sebagai instrumen.

Pengambilan data dapat dilakukan dengan cara berikut ini:

1. Data hasil belajar siswa diambil dengan menggunakan tes.

2. Data tentang kondisi pelaksanaan pembelajaran dengan mengguanakan AMBT berdasarkan lembar observasi terhadap guru dan siswa.

\subsection{Instrumen Penelitian}

Instrumen yang digunakan dalam penelitian ini berupa tes menentukan ide pokok dan 
menyimpulkan isi bacaan. Selain itu, peneliti menggunakan lembar observasi untuk menghimpun data tentang proses pelaksanaan pembelajaran.

\subsection{Teknik Analisis Data}

Untuk mengetahui tingkat kemampuan membaca pemahaman atau ketuntasan belajar, menggunakan rumus sebagai berikut:

$$
\text { Ketuntasan klasikal }=\frac{p}{n} \times 100 \%
$$

Keretanga:

$$
\begin{aligned}
& \text { P: siswa yang tuntas belajar } \\
& \text { n: Jumlah siswa }
\end{aligned}
$$

Sedangkan untuk mengetahui persentase hasil observasi menggunakan rumus:

$$
\text { Hasil Observasi } \frac{f}{t} \times 100 \%
$$

Keterangan:

$$
\begin{aligned}
& \text { f: Skor perolehan } \\
& \text { t: Skor maksimal }
\end{aligned}
$$

(Depdiknas, 2006)

\section{PEMBAHASAN}

Penelitian ini didasari oleh adanya keresahan peneliti terhadap hasil ulangan harian pada materi membaca pemahaman interpretatif siwa kelas IV SD Negri 3 Namlea pada tahun pelajaran sebelum penenelitian yakni tahun 2016/2017 dan tahun perlajaran 2017/2018. Dari empat keterampilan berbahasa, keterampilan membaca pemahaman yang paling rendah nilainya. Hal ini terlihat dari persentase ketuntasan klasikal maupun nilai rata-rata yang diperoleh siswa pada tahun pelajaran 2016/2017. Dari 28 orang siswa kelas IV hanya 17 orang yang tuntas atau $60,71 \%$ dengan nilai rata-rata 65,5 sedangkan pada tahun pelajaran 2017/2018 dari 28 orang siswa, hanya 19 orang yang tuntas atau $67,85 \%$, sedangkan standar ketuntasan minimal yang di tetapkan sekolah adalah 70\% (ketuntasan individu).

Hasil penelitian diperoleh setelah dilakukan proses pembelajaran melalui dua tahap tindakan, yaitu tindakan siklus I dan siklus II. Kedua siklus tersebut dilakukan dengan beberapa tahap yang meliputi tahap perencanaan, pelaksanaan tindakan, observasi dan evaluasi, refleksi. Setelah dilakukan proses analisis data pada siklus I dan siklus II maka dapat dilihat bahwa adanya peningkatan hasil belajar siswa kelas IV SD Negri 3 Namlea pada siklus I yang mengalami peningkatan pada siklus II dalam materi membaca pemahaman interpretatif. Selain itu, pada siklus yang sama terlihat pula adanya peningkatan aktivitas guru dan siswa dari siklus I ke siklus II. Hasil analisis dalam penelitian ini disajikan lansung dalam dua siklus. Berikut ini akan dijabarkan hasil analisis data pada siklus I dan siklus II.

\subsection{Kemampuan Membaca Pemahaman Melalui Strategi AMBT}

Hasil penelitian menunjukan bahwa penerapan strategi AMBT memiliki dampak positif dalam meningkatkan kemampuan membaca pemahaman pada siswa kelas IV SD Negri 3 Namlea. Hal ini dapat dilihat dari adanya peningkatan hasil belajar siswa pada setiap siklus. Pada tes siklus I, nilai rata-rata hasil belajar mencapai 72,5 dengan persentase ketuntasan $65 \%$, pada tes siklus II ratarata meningkat menjadi 82,9 dengan 
persentase ketuntasan 90\%. Untuk lebih jelasya mengenai peningkatan hasil belajar siswa dalam dua siklus pembelajaran disajikan pada gambar 1.1 berikut.

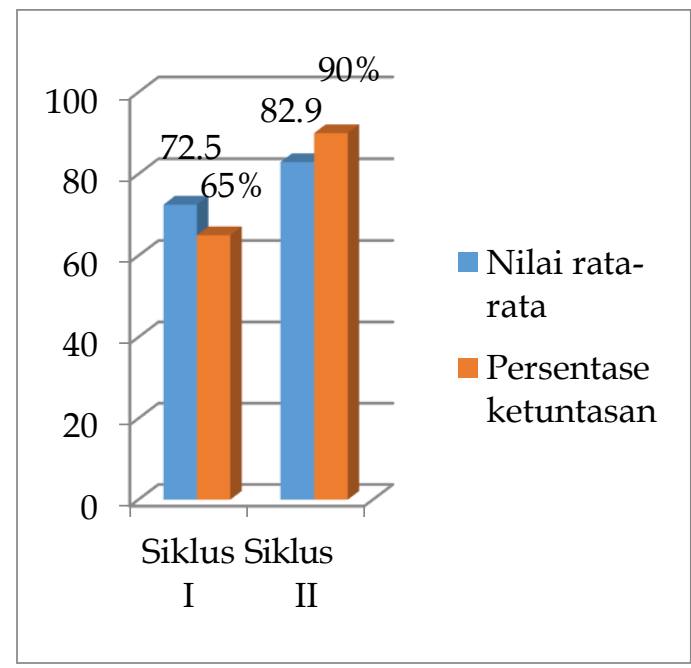

Gambar 1. Grafik Peningkatan Hasil Belajar Siswa dalam 2 Siklus

Berdasarkan grafik 1.1 di atas tampak bahwa rata-rata hasil belajar siswa mengalami peningktan dari siklus I ke siklus II. Hal ini menunjukkan bahwa penarapan strategi AMBT mempunyai dampak positif dalam meningkatkan kemampuan membaca pemahaman siswa kelas IV SD Negeri 3 Namlea yang dibuktikan dengan peningkatan hasil pembelajaranya dari siklus I ke siklus II.

\subsection{Kegiatan Guru dalam Pembelajaran}

Analisis hasil observasi kegiata guru dalam pembelajaranmenunjukan bahwa penerapan strategi AMBT di kelas IV SD Negeri 3 Namlea memiliki dampak positif dalam meningkatkan aktivitas guru. Hal ini dapat dilihat dari peningkatan hasil observasi kegiatan guru pada setiap siklus. Persentase kegiatan guru dalam melaksanakan pembelajaran pada siklus I pertemuan pertama sebesar $63,15 \%$ dan pertemuan kedua sebesar $73,68 \%$. Sedangkan pada siklus II pertemuan pertama sebesar $84,21 \%$ dan pertemuan kedua sebesar $89,47 \%$. Peningkatan aktivitas guru selama proses pembelajaran disajikan pada gambar 1.2.

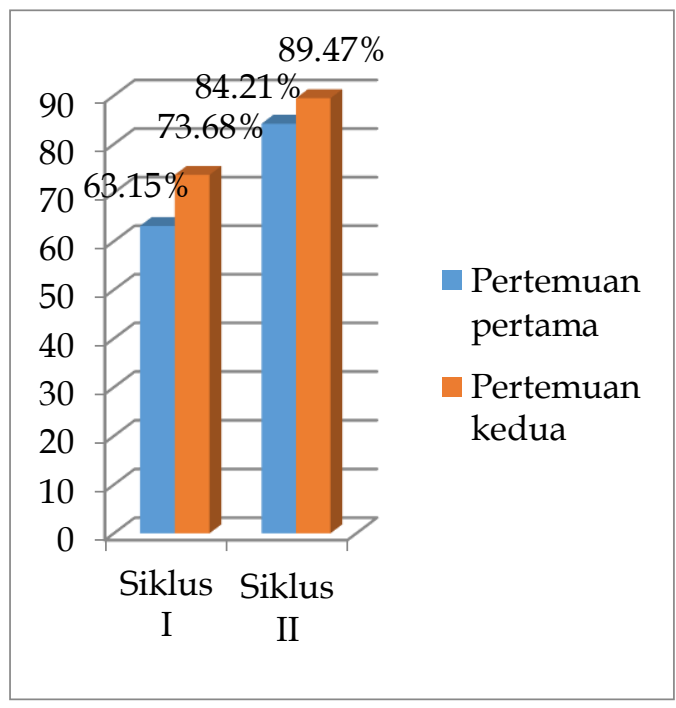

Gambar 2. Grafik Peningkatan

Persentase Aktivitas Guru dalam 2 Siklus

Berdasarkan grafik 1.2 di atas tampak bahwa persentase aktivitas guru dalam pembelajaran mengalami peningkatan dari siklus I ke siklus II, yakni pada siklus I pertemuan pertama sebesar 63,15\%, pada pertemuan kedua sebeser $73,68 \%$ sedangkan pada siklus II pertemuan pertama sebesar $84,21 \%$ dan pertemuan kedua sebesar $89,47 \%$.

\subsection{Kegiatan Siswa dalam Pembelajan}

Analisis hasil observasi kegiatan siswa dalam pembelajaran menunjukkan bahwa penerapan strategi AMBT di kelas IV SD Negeri 3 Namlea memilliki dampak positif dalam meningkatkan kemampuan membaca pemahaman. Hal ini dapat dilihat dari peningkatan hasil 
observasi kegiatan siswa pada setiap siklus. Peningkatan persentase aktivitas siswa selama proses pembelajaran selengkapnya disajikan pada gambar 1.3 berikut.

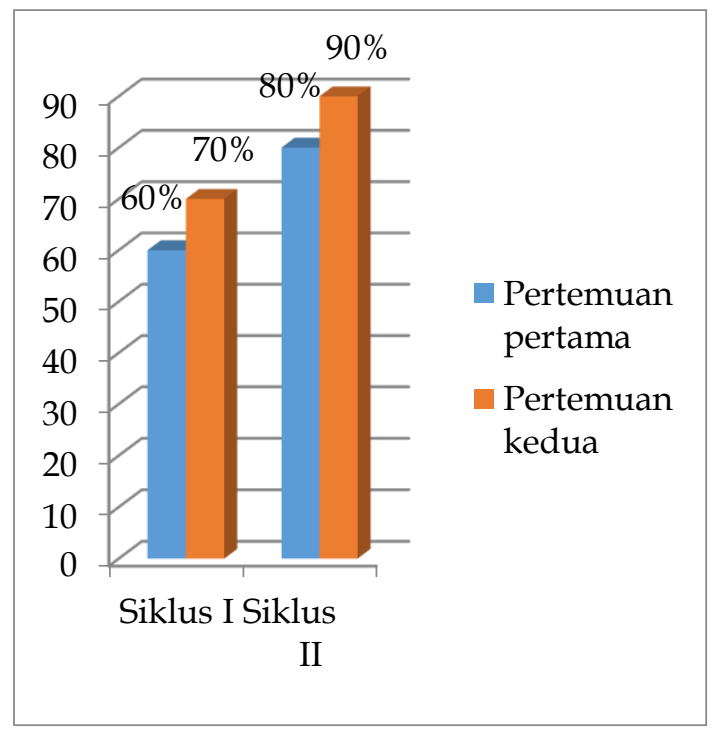

Gambar 3. Grafik Peningkatan Persentase Aktivitas Siswa Dalam 2 Siklus

Berdasarkan gambar 1.3 di atas, tampak bahwa persentase aktivitas siswa siklus I pertemuan pertama sebesar $60 \%$ dan pertemuan kedua sebesar $70 \%$ sedangkan siklus II pertemuan pertama sebesar $80 \%$ dan pertemuan kedua sebesar $90 \%$.

Pengunaan strategi aktivitas membaca berpikir terbimbing dapat meningkatkan kemampuan membaca pemahaman interpretatif siswa kelas IV SD Negeri 3 Namlea. Hal ini terbukti adanya peningkatan aktivitas guru dan siswa serta hasil belajar siswa dari siklus I ke siklus II.

Berdasarkan uraian hasil penelitian serta pembahasan dapat disimpulkan bahwa penelitian dihentikan sampai pada siklus II kerena indikator kinerja yang ditetapkan telah tercapai.

\section{PENUTUP}

Berdasarkan analisis data dan pembahasan hasil penelitian, maka dapat disimpulkan bahwa, penggunaan strategi Aktivitas Membaca Berpikir Terbimbing dapat meningkatkan proses membaca pemahaman interpretatif siswa kelas IV SD Negeri 3 Namlea, yakni rata-rata hasil belajar siswa pada siklus I sebesar 72,5 dengan persentase ketuntasan $65 \%$ meningkat pada siklus II yakni rata-rata hasil belajar siswa mencapai 82,9 dengan persentase ketuntasan $90 \%$.

Persentase aktivitas guru dalam menerapkan strategi Aktivitas Membaca Berpikir Terbimbing dalam proses pembelajaran meningkat dari siklus I ke siklus II, yakni pada siklus I pertemuan pertama sebesar $63,15 \%$ dan pertemuan kedua sebesar 73,68\% sedangkan pada siklus II Pertemuan pertama sebesar $84,21 \%$ dan pertemuan kedua sebesar $89,47 \%$.

Persentase aktivitas siswa dalam mengikuti proses pembelajaran siklus I pertemuan pertama sebesar $60 \%$ dan pertemuan kedua sebesar $70 \%$. Sedangkan pada siklus II pertemuan pertama sebesar $80 \%$ dan pertemuan kedua sebesar $90 \%$.

\section{DAFTAR PUSTAKA}

Arikunnto, S., dkk. (2007). Penelitian Tindakan Kelas. Jakarta: Bumi Aksara.

Arikunto, S. (2010). Prosedur Penelitian; Suatu Pendekatan Praktik. Yogyakarta: Rineka Cipta.

Depdiknas. (2006). Kurikulum Tingkat Satuan Pendidikan Mata Pelajaran Bahasa Indonesia. Jakarta: Depdiknas. 
Khasanah, A \& Isah, C. (2016). Peningkatan kemampuan membaca pemahaman dengan Strategi question answer relationships (qar) Pada Siswa Kelas V Sekolah Dasar. Jurnal Pedagogik Pendidikan Dasar, Volume 4 Nomor 2.

Krismanto, W; dkk. (2015). Meningkatkan kemampuan membaca pemahaman Melalui Metode Survey, Question, Read, Recite, Review (sq3r) Pada siswa kelas IV SD Negeri 46 Parepare. Jurnal Publikasi Pendidikan, Volume 5, No. 3.

Sam, B., Iye, R., Ohoibor, M., Umanailo, M. C. B., Rusdi, M., Rahman, A. B. D., \& Hajar, I. (2019). Female Feminism in the Customary Island of Buru. Int. J. Sci. Technol. Res, 8(8), 1877-1880.

Bin-Tahir, S. Z., Bugis, R., Masniati, A., Tenriawali, A. Y., Azwan, A., \& Oktavianti, D. C. (2020, January). The Role of Local Language in Intercultural Communication among Societies of Buru Island. In Proceeding of USN Kolaka-ADRI International Conference on Sustainable Coastal-Community Development (Vol. 1).

Sahid, A., Amirullah, I., Azis, A., Rachman, A. A., \& Bin-Tahir, S. Z. (2019, November). Application of Bureaucratic Accountability in Public Service. In Eastern Regional Organization for Public Administration Conference (EROPA 2018). Atlantis Press.

Mufidah, N., Suryawati, D., Sa'adah, N., \& Tahir, S. Z. B. (2019). 
LEARNING ARABIC WRITING

SKILL BASED ON DIGITAL

PRODUCTS. Ijaz Arabi Journal

of Arabic Learning, 2(2).

Farida, U., \& Bin-Tahir, S. Z. (2019, October). Bureaucratic reform of tourism sector public services in Tana Toraja Regency. In IOP Conference Series: Earth and Environmental Science (Vol. 340, No. 1, p. 012045). IOP Publishing.

Bin-Tahir, S. Z., Atmowardoyo, H., Dollah, S., Rinantanti, Y., \& Suriaman, A. (2018). MULTILINGUAL AND MONOMULTILINGUAL STUDENTS'PERFORMANCE IN ENGLISH SPEAKING. Journal of Advanced English Studies, 1(2), 32-38.

Bin-Tahir, S. Z., Suriaman, A., \& Rinantanti, Y. (2019). Designing English Syllabus for Multilingual Students at Pesantren Schools. Asian EFL Journal, 23(3.3), 5-27.

Bin Tahir, S. Z. (2015). Multilingual behavior of Pesantren IMMIM students in Makassar. Asian EFL Journal, 86, 45-64.

Amri, M., Afifuddin, A., \& Bin-Tahir, S. Z. (2018). Religious Pluralism of the Indonesian Traditional Islamic Education Institutions. The Journal of Social Sciences Research, 4(12), 446-450.

Bin Tahir, S. Z. (2017). Multilingual teaching and learning at Pesantren Schools in Indonesia. Asian EFL Journal, 89, 74-94.

Bin-Tahir, S. Z., Saidah, U., Mufidah, N., \& Bugis, R. (2018). The impact of translanguaging approach on teaching Arabic 
reading in a multilingual classroom. Ijaz Arabi Journal of Arabic Learning, 1(1).

Bin-Tahir, S. Z., Bugis, R., \& Tasiana, R. (2017). Intercultural Communication of a Multicultural Family in Buru Regency. Lingual: Journal of Language and Culture, 9(2), 8.

Nurhayati, N., \& Said, I. (2019). Emosi Verbal Suku Bajo Sampela. Sosial Budaya, 16(2), 114-126.

Aswad, H., Nurhayaty, N., \& Said, I. (2018). THE USE OF MANTRA IN THE TRADITION OF MAITAI ALLO MACOA IN ONGLO PEOPLE CAMPALAGIAN SUBDISTRICT POLMAN REGENCY: A REVIEW OF THE SEMIOTICS. JURNAL ILMU BUDAYA, 6(1).

Iye, R. (2018). Tuturan emosi mahasiswa kota baubau dalam ranah demonstrasi [emotional speech of the students in baubau city in the demonstration]. TOTOBUANG, 6 (1), 125, 138.

Iye, R., \& Susiati, S. (2018). NILAI EDUKATIF DALAM NOVEL SEBAIT CINTA DI BAWAH LANGIT KAIRO KARYA MAHMUD JAUHARI ALI (Educative Values in Sebait Cinta di Bawah Langit Kairo by Mahmud Jauhari Ali). Sirok Bastra, 6 (2), 185-191.

Susiati, S., Iye, R., \& Suherman, L. O. A. (2019). Hot Potatoes Multimedia Applications in Evaluation of Indonesian Learning In SMP Students in Buru District. ELS Journal on 
Interdisciplinary Studies in

Humanities, 2(4), 556-570.

Iye, R. Jl Prof Dr HAR Basalamah No, and Namlea-Kab Buru.". TUTURAN DALAM PROSESI LAMARAN PERNIKAHAN DI TOMIA KABUPATEN WAKATOBI." Kontemporer. Bandung: PT Remaja.

Susiati, S., \& Iye, R. (2018). Kajian Geografi Bahasa dan Dialek di Sulawesi Tenggara: Analisis Dialektometri. Gramatika: Jurnal Ilmiah Kebahasaan dan Kesastraan, 6(2), 137-151.

Susiati, S., \& Iye, R. (2018). Kajian Geografi Bahasa dan Dialek di Sulawesi Tenggara: Analisis Dialektometri. Gramatika: Jurnal Ilmiah Kebahasaan dan Kesastraan. 6 (2), 137-151.

Iye, R., Susiati, S., \& Karim, K. (2020). Citra Perempuan dalam Iklan Sabun Shinzui. Sang Pencerah: Jurnal Ilmiah Universitas Muhammadiyah Buton, 6(1), 1-7.

Iye, R. (2018). Tuturan dalam Prosesi Lamaran Pernikahan di Tomia Kabupaten Wakatobi. Jurnal Totobuang, 6(2).

Iye, R. Harziko. NILAI-NILAI MORAL DALAM TOKOH UTAMA PADA NOVEL SATIN MERAH KARYA BRAHMANTO ANINDITO DAN RIE YANTI. TELAGA BAHASA,(7), 2, 195206.

Susiati, Y. T. Risman Iye. A. Kesantunan Imperatif Bahasa Indonesia Suku Bajo Sampela: Balai Pembinaan dan Pengembangan Bahasa. 2018. Kongres Bahasa Indonesia (No. 12, pp. 1-6). Report. 
UNIQBU, P. (2019). TUTURAN

EMOSI MAHASISWA KOTA

BAU BAU.

PSP2M, T., \& Iye, R. TUTURAN

EMOSI MAHASISWA KOTA BAU BAU.

Umanailo, M. C. B., Hentihu, I., Umanailo, R., Nawawi, M., Pulhehe, S., Ohoibor, M., ... \& Bugis, R. I. K. I. (2018). Pemahaman Untuk Desa.

Umanailo, M. Chairul Basrun, Idrus Hentihu, Rosita Umanailo, Mansyur Nawawi, Sukainap Pulhehe, Mirja Ohoibor, Mohammad Faisal Sangadji et al. "Pemahaman Untuk Desa." (2018).

BURU, U. I. MODEL KOOPERATIF LEARNING TIPE STAD DALAM MENINGKATKAN KEMAMPUAN

MENGAPRESIASI CERITA FIKSI DI SD NEGERI 1 NAMLEA.

Iye, R. (2018). Tuturan emosi mahasiswa kota baubau dalam ranah demonstrasi.

No, J. S. Q., Baruga, K. K., Bassalama, J. P. A., \& Si, M. PRAANGGAPAN PAMFLET SOSIALISASI PELESTARIAN LINGKUNGAN DI KABUPATEN WAKATOBI.

Djunaidi, F. G., Azwan, A. Y. T., Iye, R., \& bin Tahir, S. Z. Decks Range Gola Village Community Begun District Buton District North.

Buru, K. M. S. PENGARUH MOTIVASI BELAJAR DI SMA 
NEGERI 2 BURU.

No, J. S. Q., Baruga, K. K., Bassalama, J. P. A., \& Si, M. PRAANGGAPAN PAMFLET SOSIALISASI PELESTARIAN LINGKUNGAN DI KABUPATEN WAKATOBI.

BURU, U. I. MODEL KOOPERATIF LEARNING TIPE STAD DALAM MENINGKATKAN KEMAMPUAN

MENGAPRESIASI CERITA FIKSI DI SD NEGERI 1 NAMLEA.

YANTI, KBADANRI. "NILAI-NILAI MORAL DALAM TOKOH UTAMA PADA NOVEL SATIN MERAH."

Buru, K. M. S. PENGARUH MOTIVASI BELAJAR DI SMA NEGERI 2 BURU.

Djunaidi, F. G., Azwan, A. Y. T., Iye, R., \& bin Tahir, S. Z. Decks Range Gola Village Community Begun District Buton District North.

Iye, R. DEIKSIS MASYARAKAT BONEGUNU KABUPATEN BUTON UTARA.

YANTI， K. NILAI-NILAI MORAL DALAM TOKOH UTAMA PADA NOVEL SATIN MERAH.

Said, Ikhwan. "EMOSI VERBAL SUKU BAJO SAMPELA."

NAMLEA, F. D. D. S. K. PERWUJUDAN ADJEKTIVA BAHASA SULA DIALEK.

YANTI， K. NILAI-NILAI MORAL DALAM TOKOH UTAMA PADA NOVEL SATIN MERAH.

BURU, U. I. MODEL KOOPERATIF LEARNING TIPE STAD DALAM MENINGKATKAN 
KEMAMPUAN

MENGAPRESIASI CERITA

FIKSI DI SD NEGERI 1

NAMLEA.

Susiati, S. (2020). Fenomena Tuturan Emosi Verbal Bahasa Indonesia Suku Bajo Sampela.

Susiati, S. (2020). Fenomena Tuturan Emosi Verbal Bahasa Indonesia Suku Bajo Sampela.

Susiati, S. (2020). Fenomena Tuturan Emosi Verbal Bahasa Indonesia Suku Bajo Sampela.

Susiati, S. (2020). Pengaplikasian Multimedia Hot Potatoes Dalam Evaluasi Pembelajaran Bahasa Indonesia Pada Siswa SMP Negeri 9 Buru.

BURU, I. PENGEMBANGAN APLIKASI MULTIMEDIA HOT POTATOES DALAM EVALUASI PEMBELAJARAN BAHASA INDONESIA PADA SISWA SMP NEGERI 9 BURU (DEVELOPMENT OF HOT POTATOES MULTIMEDIA APPLICATIONS IN EVALUATION OF INDONESIAN LEARNING IN SMP 9 STUDENTS.

Susiati, S. (2020). Kaidah Fonologi Bahasa Indonesia.

BURU, I. PENGEMBANGAN APLIKASI MULTIMEDIA HOT POTATOES DALAM EVALUASI PEMBELAJARAN BAHASA INDONESIA PADA SISWA SMP NEGERI 9 BURU (DEVELOPMENT OF HOT POTATOES MULTIMEDIA APPLICATIONS IN EVALUATION OF INDONESIAN LEARNING IN SMP 9 STUDENTS. 
FONOLOGI, M. K. KAIDAHKAIDAH FONOLOGI.

Susiati, S. (2020). Fenomena Tuturan Emosi Verbal Bahasa Indonesia Suku Bajo Sampela.

Susiati, S. (2020). Kesantunan Imperatif Bahasa Melayu Ambon.

Buru, K. M. S. PENGARUH MOTIVASI BELAJAR DI SMA NEGERI 2 BURU.

Susiati, Y. T. Risman Iye. A. Kesantunan Imperatif Bahasa Indonesia Suku Bajo Sampela: Balai Pembinaan dan Pengembangan Bahasa. 2018. Kongres Bahasa Indonesia (No. 12, pp. 1-6). Report.

Iye, R. H. NILAI-NILAI MORAL DALAM TOKOH UTAMA PADA NOVEL SATIN MERAH KARYA BRAHMANTO ANINDITO DAN RIE YANTI. TELAGA BAHASA,(7), 2, 195206.

Iye, R. Jl Prof Dr HAR Basalamah No, and Namlea-Kab Buru.". TUTURAN DALAM PROSESI LAMARAN PERNIKAHAN DI TOMIA KABUPATEN WAKATOBI." Kontemporer. Bandung: PT Remaja.

Iye, R. H. NILAI-NILAI MORAL DALAM TOKOH UTAMA PADA NOVEL SATIN MERAH KARYA BRAHMANTO ANINDITO DAN RIE YANTI. TELAGA BAHASA,(7), 2, 195206.

Susiati, S., \& Iye, R. (2018). Kajian Geografi Bahasa dan Dialek di Sulawesi Tenggara: Analisis Dialektometri. Gramatika: Jurnal Ilmiah Kebahasaan dan 
Kesastraan. 6 (2), 137-151.

Mintowati. (2003). Panduan Penulisan Buku Ajar. Depdikbud: Jakarta

Nurhadi. (2004). Pembelajaran Kontekstual dan penerapannya dalam KBK. Malang: UM Press.

Ritawati. (2005). Peningkatan Keterampilan Membaca Dan Menulis di kelas Tinggi. Jakarta: Dekdikbud.

Sugiyono. (2010). Memahami Penelitian Kualitatif. Bandung: CV Alfabeta.

Supriadi, D. (1999). Mengangkat Citra dan Martabat Guru.Yogyakarta: Adicita Karya Nusa.

Syafi'ie, (1999). Pengajaran Membaca Di Kelas-kelas Awal Sekolah Dasar. Malang: Depdiknas Universitas Negeri Malang.

Tarigan, H. (1990). Teknik Pengajaran Keterampilan Berbahasa. Bandung: Angkasa. 